\title{
Erratum to: Issue 43, 1 (2012)
}

\author{
Helmut Pulte • Gregor Schiemann
}

Published online: 29 January 2013

(C) Springer Science+Business Media Dordrecht 2013

\section{Erratum to: J Gen Philos Sci \\ DOI 10.1007/s10838-012-9192-2, 10.1007/s10838-012-9184-2,}

10.1007/s10838-012-9185-1, 10.1007/s10838-012-9176-2, 10.1007/s10838-012-9173-5, 10.1007/s10838-012-9178-0, 10.1007/s10838-012-9179-z, 10.1007/s10838-012-9180-6, 10.1007/s10838-012-9182-4, 10.1007/s10838-012-9183-3, 10.1007/s10838-012-9181-5, 10.1007/s10838-012-9177-1, 10.1007/s10838-012-9190-4, 10.1007/s10838-012-9191-3, 10.1007/s10838-012-9186-0, 10.1007/s10838-012-9187-z, 10.1007/s10838-012-9188-y

In the last issue, we published the "Special Section: What Prospects for a General Philosophy of Science." This section was guest-edited by Hans Radder. We are sorry that this important information got lost in the production process and is visible neither in the table of content nor at the front cover of that issue.

The Editors

\footnotetext{
The online version of the original article can be found under doi:10.1007/s10838-012-9192-2, 10.1007/s10838-012-9184-2, 10.1007/s10838-012-9185-1, 10.1007/s10838-012-9176-2, 10.1007/s10838-012-9173-5, 10.1007/s10838-012-9178-0, 10.1007/s10838-012-9179-z, 10.1007/s10838-012-9180-6, 10.1007/s10838-012-9182-4, 10.1007/s10838-012-9183-3, $10.1007 / \mathrm{s} 10838-012-9181-5,10.1007 / \mathrm{s} 10838-012-9177-1,10.1007 / \mathrm{s} 10838-012-9190-4$, 10.1007/s10838-012-9191-3, 10.1007/s10838-012-9186-0, 10.1007/s10838-012-9187-z, 10.1007/s10838-012-9188-y.
}

H. Pulte $(\square)$

Institut für Philosophie I, Ruhr-Universität Bochum, 44780 Bochum, Germany e-mail: helmut.pulte@rub.de

G. Schiemann $(\bowtie)$

Philosophisches Seminar, Bergische Universität Wuppertal, 42119 Bochum, Germany e-mail: schiemann@uni-wuppertal.de 